\title{
PRINCIPAIS MICRO-ORGANISMOS RESPONSÁVEIS POR INFECÇÕES RELACIONADAS À ASSISTÊNCIA EM SAÚDE (IRAS) EM UTIS: UMA REVISÃO INTEGRATIVA
}

THE MAIN MICROORGANISMS RESPONSIBLE FOR THE HEALTHCAREASSOCIATED INFECTIONS (HAIS) IN INTENSIVE CARE UNITS: AN INTEGRATIVE REVIEW

\section{Milce Costa (COSTA, M.)}

Doutora em Medicina Tropical - área de concentração: Microbiologia - IPTSP/UFGO.

Docente da Faculdade Evangélica de Ceres. Ceres - GO, Brasil.

E-mail milcebiomol@yahoo.com.br

\section{Gabriela Maria Castro Rodrigues (RODRIGUES, G.M.C)}

Acadêmico do curso de Biomedicina, Faculdade Evangélica de Ceres. Ceres - GO, Brasil.

E-mail gabicastro721@gmail.com

\section{Welington Messias Gomes (GOMES W.M.)}

Acadêmico do curso de Farmácia, Faculdade Evangélica de Ceres. Ceres - GO, Brasil. welington-messias@ hotmail.com

\section{Ademar Alves Rezende Júnior (REZENDE JÚNIOR A.A.)}

Acadêmico do curso de Farmácia, Faculdade Evangélica de Ceres. Ceres - GO, Brasil. E-mailademar.a.junior17@gmail.com

\section{Felipe Montelo Neres Cardoso (CARDOSO F.M.N.)}

Acadêmico do curso de Farmácia, Faculdade Evangélica de Ceres. Ceres - GO, Brasil. E-mailfelipemonteloneres@gmail.com

Endereço para correspondência: Av. Brasil, s/n - Setor Morada Verde, Ceres - GO. Brasil CEP 76300-000 e-mail: milcebiomol@ yahoo.com.br 


\title{
RESUMO
}

INTRODUÇÃO: As infecções relacionadas à assistência em saúde (IRAS) são as infecções adquiridas em unidade hospitalar que serão manifestadas após ou durante a internação, ou mesmo posteriormente à alta hospitalar desde que presentes fatores relacionados à hospitalização. OBJETIVO: Verificar os principais micro-organismos causadores destas infecções em hospitais brasileiros no período compreendido entre 2000 a 2016, bem como verificar a predominância do sítio anatômico mais acometido. METODOLOGIA: Trata-se de um estudo de revisão integrativa, por meio de levantamento bibliográfico e através da análise dos resultados. Os dados foram coletados nas bases eletrônicas Biblioteca Virtual de Saúde (BVS), SciELO, LILACS e BIREME no período de 2000 a 2016. Foram analisadas 14 publicações nacionais. RESULTADOS E DISCUSSÃO: Dentre os 42 micro-organismos encontrados causando IRAS em Unidade de Terapia Intensiva (UTI) destacam-se a Pseudomonas aeruginosa relatada em $10(23,8 \%)$ dos artigos selecionados, seguida do Staphylococcus aureus e Acinetobacter baumanni citados em 14,3\% dos artigos. A Klebsiella pneumoniae aparece em $5(11,7 \%)$ dos artigos analisados. Quanto aos 42 sítios anatômicos mais acometidos, verificou-se a superioridade dos casos de IRAS pela via do trato respiratório e trato urinário, com $33,2 \%$ e $31 \%$ dos casos descritos respectivamente. As infecções de corrente sanguínea e sepse perfazem um total de 14,3\% e 11,9\% dos casos analisados respectivamente. CONCLUSÃO: Apesar da implantação de práticas voltadas para prevenção de IRAS em UTI serem amplamente divulgadas, a efetiva adesão dos profissionais nos serviços de saúde ainda é incipiente. Dessa forma, os indivíduos envolvidos devem redobrar a atenção quanto ao uso de medidas assépticas e constante lavagem das mãos, na rotina dos cuidados.

Palavras-chaves: Infecção nosocomial. UTI. Local da infecção. Prevalência.

\begin{abstract}
INTRODUCTION: The healthcare-associated Infections (HAIs) are any infection acquired in a hospital unit which will be manifested after or during hospitalization. It can also occur after hospital discharge, as long as there are factors related to hospitalization. OBJECTIVES: To verify the main microorganisms that cause these infections in Brazilian hospitals in the period from 2000 to 2016, as well as to verify the predominance of the most affected anatomical site. METHODOLOGY: It is an integrative review study carried out by a bibliographic survey and by the analysis of the results. The data were collected in the electronic bases BVS, SciELO, LILACS and BIREME in the period of 2000 to 2016. A total of 14 national publications were analyzed. RESULTS AND DISCUSSION Among the 42 microorganisms found to cause HAIs in Intensive Care Units (ICU), stand Pseudomonas aeruginosa reported in 10 (23.8\%) of the selected articles, follow by Staphylococcus aureus, Acinetobacter baumannii related in $14.3 \%$ of the articles. Klebsiella pneumoniae reported in 5 $(11.7 \%)$ of the analyzed articles. Regarding the 42 most affected anatomical sites, it was found the superiority of cases of HAI through the respiratory tract and urinary tract, with $33.2 \%$ and $31 \%$ of the cases described respectively. Bloodstream infections and sepsis make up a total of $14.3 \%$ and $11.9 \%$ of the cases analyzed respectively. CONCLUSION: Although the implementations of practices aimed at the prevention of IRAS in ICU are widely publicized, the effective adhesion of professional in health services is still elementary. Thus,
\end{abstract}


individuals involved must redouble their attention to the use of aseptic measures and constant hand washing in the routine of care.

Keywords: Nosocomial infection. ICU. Infection site. Prevalency.

\section{INTRODUÇÃO}

A infecção hospitalar ou infecção nosocomial (IN), também designada de forma mais abrangente como infecções relacionadas a assistência à saúde (IRAS) é definida como toda infecção adquirida em unidade hospitalar que será manifestada após ou durante a internação, ou mesmo posteriormente à alta hospitalar desde que presentes fatores relacionados à hospitalização. Normalmente são utilizados alguns critérios para diagnosticar as IRAS, como aqueles relacionados ao surgimento das manifestações clínicas (sinais e sintomas) e comprovação laboratorial (exames microbiológicos, histopatológicos e sorológicos) à partir de 72 horas após o período de internação do paciente, podendo também ocorrer em um período menor de tempo, quando a infecção está relacionada com procedimentos invasivos (OMS, 2008).

Em países subdesenvolvidos os casos de IRAS apresentam índices mais elevados em relação aos países desenvolvidos. No Brasil as IRAS são consideradas um grave problema de saúde pública, apresentando taxas de 22,8\% quando comparado aos países desenvolvidos europeus cujas taxas são menores que 9\%. Ao avaliar dados específicos de IRAS por região no Brasil, destacam-se os seguintes percentuais: região sudeste com $16,4 \%$, região nordeste com $13,1 \%$, região norte com $11,5 \%$, região sul com $9 \%$ e região centro-oeste com $7,2 \%$ dos casos descritos (MOURA, et al., 2007; MOURA et al., 2008; GRAY; OMAR, 2013; ROMANELLI et al, 2013).

No Brasil verifica-se que as IRAS são a quarta causa de mortalidade em Unidade de Terapia Intensiva (UTI), no entanto, os dados disponíveis não são claramente divulgados ou estão obsoletos. Além disso, muitos hospitais não consolidam suas informações gerando uma grande dificuldade em se conhecer a extensão deste problema no país (ABEGG; SILVA, 2011). Dessa forma, informações precisas da dimensão do problema no país ficam prejudicadas. Dados da Agência Nacional de Biossegurança (ANBIO) mostram que 80\% dos hospitais não fazem o controle adequado das infecções hospitalares, sendo possível presumir que as instituições hospitalares não divulgam seus dados através de artigos científicos ao 
público, tornando-se difícil obter dados recentes com o panorama real das infecções hospitalares no Brasil (OLIVEIRA; KOVNER; SILVA, 2010; ANBIO 2012).

Alguns fatores, considerados de risco, propiciam a ocorrência de IRAS em pacientes de UTI. Ao comparar os pacientes hospitalizados em UTIs, com as demais unidades hospitalares, verifica-se que a vulnerabilidade destes às IRAS se fazem notórias em virtude do grave comprometimento em sua resposta imunológica, decorrente tanto da doença que originou a infecção, quanto pelas intervenções necessárias para diagnósticos e tratamento. É de grande relevância considerar que os procedimentos invasivos de alta complexidade, cirurgias complexas, medicamentos imunossupressores e o contato direto com a equipe de saúde podem aumentar o risco de aquisição de infecções em UTIs. Outro fator agravante para o paciente em unidade intensiva é a necessidade da utilização de antimicrobianos de amplo espectro, que por sua vez contribuem para a seleção de bactérias multirresistentes (PEREIRA et al, 2000; VINCENT, 2003; COUTO; PEDROSA; NOGUEIRA, 2003; PILONETTO et al, 2004).

Diante do quadro clínico vulnerável dos pacientes internados em UTIs, inúmeras infecções circulam neste local. Dentre elas destacam-se as pneumonias (geralmente associada a ventilação mecânica), infecções do trato urinário (associada a dispositivos intravesicais), as bacteremias (associada a cateter venoso central) e as infecções de feridas operatórias, perfazendo mais de $80 \%$ de todas as IRAS. Ao analisar as IRAS descritas, pode-se identificar a prevalência de alguns micro-organismos com maior frequência como o Staphylococcus aureus, Klebsiella pneumoniae, Pseudomonas aeruginosa e Candida spp todos apresentando risco potencial para pacientes com imunidade comprometida (NOGUEIRA et al, 2009; OLIVEIRA; KOVNER; SILVA, 2010; CAVALEIRO, 2011).

A fim de se evitar a contaminação dos pacientes de UTI com micro-organismos patogênicos é fundamental empregar medidas de higiene específicas para prevenção de infecções neste ambiente. Segundo a Organização Mundial de Saúde (OMS), a prática da higienização das mãos com água e sabão e preparações alcoólicas configura-se numa medida fundamental para a prevenção de infeções e contribui para a segurança de pacientes e profissionais. Além da lavagem das mãos, deve-se estabelecer sistematicamente a desinfecção apropriada dos dispositivos invasivos utilizados, materiais e superfícies, bem como a adoção do uso dos Equipamentos de Proteção Individual (EPI). Visando a redução da incidência de IRAS, uma das principais medidas profiláticas é dirigida pela portaria $n^{\circ} 2.616 / 1998$ da Agência Nacional de Vigilância Sanitária (ANVISA), e do Ministério da Saúde (MS). A 
portaria orienta sobre a constituição do Programa de Controle de Infecção Hospitalar (PCIH) exigindo dos hospitais a constituição da Comissão de Controle de Infecção Hospitalar (CCIH) (GUEDES et al, 2012; BARBOSA, SIQUEIRA, MANTOVANI, 2012; FRANÇA et al, 2013; ANVISA, 2009; BRASIL, 1998).

O presente estudo teve como objetivo descrever os principais micro-organismos causadores de IRAS em trabalhos publicados entre 2000 a 2016, bem como verificar a predominância do sítio anatômico mais acometido. Ao analisar estes aspectos, foram ressaltadas a importância de programas de prevenção e da incorporação correta do funcionamento das CCIHs nas instituições de saúde objetivando diminuir a ocorrência das IRAS.

\section{METODOLOGIA}

Trata-se de um estudo de revisão integrativa no qual a coleta de dados foi realizada a partir de estudos originais, por meio de levantamento bibliográfico e através da análise dos resultados no período compreendido entre agosto a outubro de 2018. A busca de produção científica indexada foi realizada nas seguintes bases eletrônicas: Biblioteca Virtual de Saúde (BVS), SciELO (Biblioteca Eletrônica Científica Online), LILACS (Literatura Latino Americana e do Caribe em Ciências de Saúde) e BIREME (Centro Latino Americano e do Caribe de Informação em Ciências da Saúde). Os descritores utilizados foram relacionados à prevalência de infecções nosocomiais em Unidades de Terapia Intensiva (UTI) nas diferentes regiões do Brasil e combinados da seguinte forma: infecção nosocomial, infecção hospitalar, UTI, estudo epidemiológico, prevalência, local da infecção.

Foram incluídos no estudo: artigos científicos indexados nos bancos de dados citados, artigos completos, disponíveis online e com os descritores em saúde propostos. Os critérios de inclusão para seleção dos artigos foram: (a) pesquisas que abordaram a prevalência de infecções nosocomiais em UTIs nas diferentes regiões do Brasil; (b) artigos publicados no período compreendido entre 2000 a 2016; (c) artigos em português, inglês ou espanhol. O período de tempo definido para realização do trabalho (últimos 16 anos) foi em virtude da atualidade do tema, bem como da extensão do tempo observado. Foram excluídos: (a) os artigos que não apresentaram como objetivo principal a prevalência de infecções nosocomiais em UTIs nas diferentes regiões do Brasil; (b) artigos repetidos; e (c) editoriais, cartas, comentários, revisões, relato de caso, dissertações ou teses. 
Após selecionados os artigos, realizou-se uma leitura exploratória, seguida de leitura analítica e interpretativa. Dessa forma, foi possível a criação de quatro categorias abordando os principais pontos a serem discutidos: (a) caracterização dos artigos científicos; (b) principais micro-organismos causadores de IRAS em UTI; (c) os principais sítios anatômicos acometidos por IRAS em UTI e (d) medidas preventivas de IRAS em UTI.

Para realização da análise estatística descritiva, os dados foram inseridos em tabelas do programa Microsoft Office Excel 2010 para Windows onde as variáveis foram apresentadas em seus valores absolutos e relativos.

\section{RESULTADOS E DISCUSSÃO}

\section{Caracterização dos artigos científicos}

Através desta revisão foi possível apresentar um perfil das IRAS em UTIs no Brasil no período compreendido entre 2000 a 2016. O Quadro 1 apresenta os 14 artigos selecionados e analisados conforme os critérios indicados na metodologia deste estudo. Informações sobre o objetivo, micro-organismo responsável, sítio anatômico da infecção e região do Brasil foram demonstradas.

Quadro 1: Distribuição dos estudos científicos publicados sobre IRAS em UTIs nas diferentes regiões do Brasil no período entre 2000 a 2016.

\begin{tabular}{|c|c|c|c|c|}
\hline REFERÊNCIAS & OBJETIVOS & $\begin{array}{c}\text { PRINCIPAL } \\
\text { MICRO- } \\
\text { ORGANISMO }\end{array}$ & $\begin{array}{c}\text { PRINCIPAIS } \\
\text { SÍTIOS } \\
\text { ANATÔMICOS } \\
\text { ACOMETIDOS }\end{array}$ & $\begin{array}{c}\text { REGIÃO } \\
\text { DO } \\
\text { BRASIL }\end{array}$ \\
\hline $\begin{array}{l}\text { LEISER, J. J; TOGNIM, } \\
\text { M. C. B.; BEDENDO, J. } \\
\text { Infecções hospitalares } \\
\text { em um centro de terapia } \\
\text { intensiva de um hospital }\end{array}$ & $\begin{array}{l}\text { Determinar a incidência da } \\
\text { infecção hospitalar em um } \\
\text { centro de terapia intensiva, } \\
\text { identificar os principais } \\
\text { agentes etiológicos destas }\end{array}$ & $\begin{array}{c}\text { Staphylococcus } \\
\text { aureus }\end{array}$ & $\begin{array}{l}\text { Vias aéreas, } \\
\text { Trato urinário } \\
\text { Sítio cirúrgico }\end{array}$ & Sul \\
\hline
\end{tabular}




\begin{tabular}{|c|c|c|c|c|}
\hline $\begin{array}{l}\text { de ensino no norte do } \\
\text { Paraná. Ciência, cuidado } \\
\text { e saúde, v. 6, n. } 2 \text {, p. } 181 \text { - } \\
\text { 186, } 2007 \text {. }\end{array}$ & $\begin{array}{c}\text { envolvidos na etiologia } \\
\text { das infecções hospitalares, } \\
\text { avaliar o perfil de } \\
\text { sensibilidade } \\
\text { antimicrobiana dos agentes } \\
\text { etiológicos às drogas } \\
\text { antimicrobianas } \\
\text { usualmente empregadas na } \\
\text { rotina clínica, identificar a } \\
\text { taxa de infecção hospitalar } \\
\text { por topografia, determinar } \\
\text { a taxa de letalidade } \\
\text { ocasionada pelas infecções } \\
\text { hospitalares. }\end{array}$ & & & \\
\hline $\begin{array}{l}\text { BARROS L.M et al. } \\
\text { Prevalência de } \text { micro- } \\
\text { organismo } \\
\text { sensibilidade } \\
\text { antimicrobiana } \\
\text { infecções hospitalares em } \\
\text { unidade de terapia } \\
\text { intensiva de hospital } \\
\text { público no Brasil. } \\
\text { Revista de Ciências } \\
\text { Farmacêuticas Básica e } \\
\text { Aplicada, v. 33, n. 3, p. } \\
\text { 429-435, 2012. }\end{array}$ & $\begin{array}{l}\text { Identificar a prevalência, o } \\
\text { setor, o micro-organismo e } \\
\text { a sensibilidade } \\
\text { antimicrobiana de } \\
\text { infecções hospitalares em } \\
\text { UTI de hospital público } \\
\text { terciário. }\end{array}$ & $\begin{array}{c}\text { Staphylococcus } \\
\text { aureus }\end{array}$ & $\begin{array}{l}\text { Vias aéreas } \\
\text { Trato urinário } \\
\text { Corrente Sanguír }\end{array}$ & Nordeste \\
\hline $\begin{array}{l}\text { MOURA M.E.B et al. } \\
\text { Infecção } \text { hospitalar: } \\
\text { estudo de prevalência em }\end{array}$ & $\begin{array}{c}\text { Determinar a prevalência } \\
\text { de infecções hospitalares } \\
\text { (IH) nas unidades de }\end{array}$ & $\begin{array}{c}\text { Klebsiella } \\
\text { pneumoniae }\end{array}$ & $\begin{array}{c}\text { Vias aéreas } \\
\text { Trato urinário } \\
\text { Corrente }\end{array}$ & Nordeste \\
\hline
\end{tabular}




\begin{tabular}{|c|c|c|c|c|}
\hline $\begin{array}{l}\text { um hospital público de } \\
\text { ensino. Rev. Bras. } \\
\text { Enferm, v.60, n.4, p. } \\
\text { 416-42, } 2007 .\end{array}$ & $\begin{array}{l}\text { terapia intensiva de um } \\
\text { hospital público e de } \\
\text { ensino }\end{array}$ & & sanguínea & \\
\hline $\begin{array}{l}\text { NOGUEIRA, P. S. F et } \\
\text { al. Perfil da infecção } \\
\text { hospitalar em um } \\
\text { hospital universitário. } \\
\text { Rev. enferm UERJ, v. } \\
\text { 17, n. 1, p. 96-101, 2009. }\end{array}$ & $\begin{array}{c}\text { Analisar quais as IH } \\
\text { prevalentes } \\
\text { no hospital universitário } \\
\text { de nossa atuação, quais os } \\
\text { patógenos mais presentes } \\
\text { nessas infecções e seu } \\
\text { perfil de sensibilidade aos } \\
\text { antimicrobianos. }\end{array}$ & $\begin{array}{c}\text { Klebsiella } \\
\text { pneumoniae }\end{array}$ & $\begin{array}{l}\text { Vias aéreas } \\
\text { Corrente } \\
\text { sanguínea } \\
\text { Trato urinário }\end{array}$ & Sudeste \\
\hline $\begin{array}{l}\text { CÂNDIDO, R. B. R et } \\
\text { al. Avaliação das } \\
\text { infecções hospitalares em } \\
\text { pacientes críticos em um } \\
\text { Centro de Terapia } \\
\text { Intensiva. Revista da } \\
\text { Universidade Vale do } \\
\text { Rio Verde, v. 10, n. } 2 \text {, } \\
2012 \text {. }\end{array}$ & $\begin{array}{l}\text { Determinar a prevalência } \\
\text { de infecção hospitalar, no } \\
\text { Centro de } \\
\text { Tratamento Intensivo, } \\
\text { verificar a distribuição por } \\
\text { topografia e por micro- } \\
\text { organismos e suas } \\
\text { sensibilidades } \\
\text { microbianas. }\end{array}$ & $\begin{array}{c}\text { Staphylococcus } \\
\text { aureus }\end{array}$ & $\begin{array}{c}\text { Vias aéreas } \\
\text { Trato urinário } \\
\text { Corrente } \\
\text { sanguínea }\end{array}$ & Sudeste \\
\hline $\begin{array}{l}\text { ABREU, K. E. O et al. } \\
\text { Infecção hospitalar em } \\
\text { uma unidade de terapia } \\
\text { intensiva de um hospital } \\
\text { público. Revista do } \\
\text { Hospital Universitário } \\
\text { UFMA, v. 9, p. 31-36, }\end{array}$ & $\begin{array}{l}\text { Investigar a percepção dos } \\
\text { clientes sobre a assistência } \\
\text { prestada dentro da UTI, } \\
\text { identificar se os pacientes } \\
\text { foram ou não informados a } \\
\text { respeito de sua internação, } \\
\text { patologia, tratamento e }\end{array}$ & $\begin{array}{c}\text { Acinetobacter } \\
\text { baumannii }\end{array}$ & $\begin{array}{c}\text { Vias aéreas } \\
\text { Corrente } \\
\text { sanguínea } \\
\text { Trato urinário }\end{array}$ & Nordeste \\
\hline
\end{tabular}




\begin{tabular}{|c|c|c|c|c|}
\hline 2008. & $\begin{array}{c}\text { evolução clínica da } \\
\text { doença, verificar se as } \\
\text { necessidades dos pacientes } \\
\text { estão sendo atendidas } \\
\text { satisfatoriamente e analisar } \\
\text { situações positivas e } \\
\text { negativas, implicando a } \\
\text { assistência ao paciente na } \\
\text { UTI. }\end{array}$ & & & \\
\hline $\begin{array}{l}\text { SANTOS, A. K. S et al. } \\
\text { Perfil microbiológico das } \\
\text { infecções hospitalares } \\
\text { nas unidades de terapia } \\
\text { intensiva. Revista de } \\
\text { enfermagem UFPE, v. } \\
\text { 10, n. 3, p. 1432-1440, } \\
2015 .\end{array}$ & $\begin{array}{c}\text { Investigar o perfil } \\
\text { microbiológico das } \\
\text { infecções hospitalares nas } \\
\text { unidades de terapia } \\
\text { intensiva. }\end{array}$ & $\begin{array}{c}\text { Klebsiella } \\
\text { pneumoniae }\end{array}$ & $\begin{array}{l}\text { Vias aéreas } \\
\text { Sítio cirúrgico } \\
\text { Trato urinário }\end{array}$ & Nordeste \\
\hline $\begin{array}{l}\text { FAVARIN, S. S.; } \\
\text { CAMPONOGARA, S. } \\
\text { Perfil dos pacientes } \\
\text { internados na unidade de } \\
\text { terapia intensiva adulto } \\
\text { de um hospital } \\
\text { universitário. Revista de } \\
\text { Enfermagem da UFSM, } \\
\text { v. 2, n. 2, p. 320-329, } \\
\text { 2012. }\end{array}$ & $\begin{array}{l}\text { Descrever o perfil dos } \\
\text { pacientes internados na } \\
\text { Unidade de Terapia } \\
\text { Intensiva Adulto de um } \\
\text { hospital universitário. }\end{array}$ & $\begin{array}{c}\text { Pseudomonas } \\
\text { aeruginosa }\end{array}$ & $\begin{array}{c}\text { Vias aéreas } \\
\text { Corrente } \\
\text { sanguínea } \\
\text { Trato urinário }\end{array}$ & Sul \\
\hline $\begin{array}{l}\text { PADRÃO, M. C et al. } \\
\text { Prevalência de infecções } \\
\text { hospitalares em unidade }\end{array}$ & $\begin{array}{l}\text { Avaliar a prevalência e o } \\
\text { perfil microbiológico das } \\
\text { IH na UTI, bem como a }\end{array}$ & $\begin{array}{l}\text { Proteus } \\
\text { mirabilis }\end{array}$ & $\begin{array}{l}\text { Trato urinário } \\
\text { Vias aéreas } \\
\text { Sítio cirúrgico }\end{array}$ & Sudeste \\
\hline
\end{tabular}




\begin{tabular}{|c|c|c|c|c|}
\hline $\begin{array}{l}\text { de terapia intensiva. Rev } \\
\text { Bras Clin Med, v. } 8 \text {, n. } 2 \text {, } \\
\text { p. } 125-8,2010 \text {. }\end{array}$ & $\begin{array}{c}\text { evolução dos pacientes } \\
\text { notificados. }\end{array}$ & & & \\
\hline $\begin{array}{l}\text { FIGUEIREDO, D. A.; } \\
\text { VIANNA, R. P. T.; } \\
\text { NASCIMENTO, J. A. } \\
\text { Epidemiologia } \\
\text { infecção hospitalar em } \\
\text { uma Unidade de Terapia } \\
\text { Intensiva de um hospital } \\
\text { público municipal de } \\
\text { João Pessoa-PB. Revista } \\
\text { Brasileira de Ciências da } \\
\text { Saúde, v. 17, n. 3, p. 233- } \\
\text { 240, 2013. }\end{array}$ & $\begin{array}{c}\text { Descrever a epidemiologia } \\
\text { das infecções hospitalares } \\
\text { em uma UTI de um } \\
\text { Hospital Público } \\
\text { Municipal. }\end{array}$ & $\begin{array}{c}\text { Pseudomonas } \\
\text { aeruginosa }\end{array}$ & $\begin{array}{c}\text { Corrente } \\
\text { sanguínea } \\
\text { Vias aéreas } \\
\text { Trato urinário }\end{array}$ & Nordeste \\
\hline $\begin{array}{l}\text { LISBOA, T. C et al. } \\
\text { Prevalência de infecção } \\
\text { nosocomial em Unidades } \\
\text { de Terapia Intensiva do } \\
\text { Rio Grande do Sul. Rev. } \\
\text { bras. ter. intensiva, v. 19, } \\
\text { n. 4, p. 414-420, } 2007 .\end{array}$ & $\begin{array}{l}\text { Avaliar prospectivamente } \\
\text { os pacientes críticos } \\
\text { segundo idade, condições } \\
\text { clínicas, tempo de } \\
\text { hospitalização, ocorrência } \\
\text { de infecção hospitalar, } \\
\text { topografia da infecção } \\
\text { hospitalar, ocorrência ou } \\
\text { não de multirresistência } \\
\text { microbiana, uso de pro- } \\
\text { cedimentos invasivos e de } \\
\text { antimicrobianos. }\end{array}$ & $\begin{array}{l}\text { Staphylococcus } \\
\text { aureus }\end{array}$ & $\begin{array}{c}\text { Vias aéreas } \\
\text { Trato urinário } \\
\text { Corrente } \\
\text { sanguínea }\end{array}$ & Sul \\
\hline $\begin{array}{l}\text { LIMA, } \quad \text { M. } \quad \text { E.; } \\
\text { ANDRADE, } \\
\text { V. } \quad \text { J. }\end{array}$ & $\begin{array}{l}\text { Avaliar prospectivamente } \\
\text { os pacientes críticos } \\
\text { segundo idade, condições }\end{array}$ & $\begin{array}{l}\text { Pseudomonas } \\
\text { aeruginosa, }\end{array}$ & $\begin{array}{l}\text { Vias aéreas } \\
\text { Corrente } \\
\text { sanguínea }\end{array}$ & Sudeste \\
\hline
\end{tabular}




\begin{tabular}{|c|c|c|c|c|}
\hline $\begin{array}{l}\text { prospectiva da ocorrência } \\
\text { de infecção em pacientes } \\
\text { críticos de unidade de } \\
\text { terapia intensiva. Rev. } \\
\text { bras. ter. intensiva, v. } 19 \text {, } \\
\text { n. } 3 \text {, p. 342-7, } 2007 \text {. }\end{array}$ & $\begin{array}{c}\text { clínicas, tempo de } \\
\text { hospitalização, ocorrência } \\
\text { de infecção hospitalar, } \\
\text { topografia da infecção } \\
\text { hospitalar, ocorrência ou } \\
\text { não de multiresistência } \\
\text { microbiana, uso de pro- } \\
\text { cedimentos invasivos e de } \\
\text { antimicrobianos. }\end{array}$ & & Trato urinário & \\
\hline $\begin{array}{l}\text { RODRIGUES, A. M. X.; } \\
\text { PAZ, I. F. R.; FREITAS, } \\
\text { R. M. Problemas } \\
\text { Relacionados } \quad \text { com } \\
\text { Antimicrobianos em UTI } \\
\text { em um Hospital Público } \\
\text { de Teresina Revista } \\
\text { Multiprofissional em } \\
\text { Saúde do Hospital São } \\
\text { Marcos, v. 1, n. 1, p. 40- } \\
\text { 9, } 2013 .\end{array}$ & $\begin{array}{c}\text { Investigar os principais } \\
\text { problemas relacionados } \\
\text { com o uso de } \\
\text { Antimicrobianos no } \\
\text { tratamento de infecções } \\
\text { dentro de uma Unidade de } \\
\text { Terapia Intensiva (UTI) } \\
\text { em um Hospital Público } \\
\text { do município de Teresina, } \\
\text { Piauí. }\end{array}$ & $\begin{array}{c}\text { Acinetobacter } \\
\text { baumannii }\end{array}$ & $\begin{array}{c}\text { Vias aéreas } \\
\text { Cutânea } \\
\text { Partes moles }\end{array}$ & Nordeste \\
\hline $\begin{array}{l}\text { OLIVEIRA, A. C.; } \\
\text { KOVNER, C. T.; SILVA } \\
\text { R. S. Infecção hospitalar } \\
\text { em unidade de } \\
\text { tratamento intensivo de } \\
\text { um hospital universitário } \\
\text { brasileiro. Revista } \\
\text { Latino-Americana de } \\
\text { Enfermagem, v. 18, n. 2, } \\
\text { 2010. }\end{array}$ & $\begin{array}{c}\text { Determinar a incidência } \\
\text { das infecções hospitalares, } \\
\text { sua associação com } \\
\text { características clínicas } \\
\text { (sexo, idade, procedência, } \\
\text { tipo de paciente, tempo de } \\
\text { permanência (dias), } \\
\text { infecção comunitária, } \\
\text { colonização por } \\
\text { microrganismos } \\
\text { resistentes, uso de }\end{array}$ & $\begin{array}{c}\text { Acinetobacter } \\
\text { baumannii }\end{array}$ & $\begin{array}{c}\text { Vias aéreas } \\
\text { Trato urinário } \\
\text { Sepse }\end{array}$ & Sudeste \\
\hline
\end{tabular}




\begin{tabular}{|c|c|c|c|c|}
\hline & $\begin{array}{c}\text { procedimentos invasivos e } \\
\text { óbitos) e seus sítios de } \\
\text { ocorrência. }\end{array}$ & & & \\
\hline
\end{tabular}

Nos 14 artigos selecionados, verificou-se a presença de 42 micro-organismos como os principais responsáveis por IRAS em UTIs (Tabela 1).

Tabela 1. Principais micro-organismos causadores de IRAS em Unidades de Terapia Intensiva, distribuídos entre os estudos analisados (N) no período de 2000 a 2016.

\begin{tabular}{lcc}
\hline \multicolumn{1}{c}{ Micro-organismos } & $\mathrm{N}$ & $\%$ \\
\hline Pseudomonas aeruginosa & 10 & 23,8 \\
Staphylococcus aureus & 6 & 14,3 \\
Acinetobacter baumannii & 6 & 14,3 \\
Klebsiella pneumoniae & 5 & 11,7 \\
Acinetobacter sp & 4 & 9,5 \\
Pseudomonas spp & 2 & 4,8 \\
Klebsiella spp & 2 & 4,8 \\
Staphylococcus spp & 1 & 2,4 \\
Staphylococcus coagulase negativa & 1 & 2,4 \\
Proteus mirabilis & 1 & 2,4 \\
MRSA (Staphylococcus aureus Meticilina Resistente) & 1 & 2,4 \\
Enterobacter aerogenes & 1 & 2,4 \\
Citrobacter koseri & 1 & 2,4 \\
BGN (Bacilos Gram Negativos Não Fermentadores) & 1 & 2,4 \\
Total & 42 & 100 \\
\hline
\end{tabular}

Dentre os 42 micro-organismos encontrados causando IRAS em UTI destacam-se a Pseudomonas aeruginosa relatada em 10 (23,8\%) dos artigos selecionados, seguida do Staphylococcus aureus e do Acinetobacter baumanni citados em 14,3\% dos artigos. A Klebsiella pneumoniae aparece em $5(11,9 \%)$ dos artigos analisados.

Outros autores também relatam a presença frequente de Pseudomonas aeruginosa, Staphylococcus aureus, Acinetobacter baumanni e Klebsiella pneumoniae em ambiente de UTI. Estima-se que 2/3 das IRAS em pacientes internados nesta unidade hospitalar são provenientes da própria microbiota comensal dos indivíduos, apresentando risco potencial 
para aqueles pacientes com imunidade comprometida (RENNER; CARVALHO, 2013; BARROS, et al, 2012).

A Pseudomonas aeruginosa é uma bactéria patogênica ubiquitária e oportunista. Embora raramente possa ocasionar patologias em indivíduos sadios, estes micro-organismos são uma grande ameaça a pacientes hospitalizados, particularmente aqueles que apresentam doenças de base. Esta bactéria causa bacteremia principalmente em indivíduos com infecção urinária associada ao uso de cateteres e em vítimas de queimaduras, é responsável ainda por pneumonias em pacientes internados em UTI (TSAKRIS et al, 2000). A Pseudomonas aeruginosa tem sido descrita com um importante agente causal de IRAS em UTIs por sua grande habilidade em sobreviver em locais de umidade elevada como pias, aparelhos de ventilação respiratória, equipamentos hospitalares com presença de componentes líquidos fluídos de administração intravenosa, e até mesmo em sabonete líquido antibacteriano e desinfetantes (BICUDO, et al. 2007; GLOWACKI, et al. 2016).

O Staphylococcus aureus é considerado um dos principais micro-organismos causadores de IRAS adquiridas tanto na comunidade quanto em ambiente hospitalar. Habitualmente o $S$. aureus é comensal das fossas nasais, garganta, pele e intestino de indivíduos sadios. Dessa forma, as infecções frequentemente são em decorrência da introdução desta bactéria em sítios anatômicos após um trauma, lesões de pele e mucosas, durante procedimentos cirúrgicos e inserção de dispositivos invasivos, principalmente em UTI. Este micro-organismo apresenta grande relevância clínica por sua elevada frequência e patogenicidade, bem como por sua fácil disseminação intra- hospitalar (por meio de aerossóis e mãos dos profissionais de saúde). Estes fatores associados à resistência aos antibióticos, torna-o capaz de produzir doenças tanto em indivíduos hígidos como em imunocomprometidos (CARVALHO, C. et al,2005; MENEGOTTO; PICOLI, 2007; SANTOS, et al, 2007).

É importante relatar que a colonização nasal por S. aureus é assintomática. Sendo assim, representa grande importância clínica, tendo em vista que o hospedeiro assintomático pode ser um visitante ou mesmo um profissional da saúde, que em contato com paciente internado carreia o micro-organismo através das mãos e aerossóis provenientes das vias aéreas, estabelecendo assim uma fonte potencial de infecção nestes ambientes e levando a quadros de IRAS (CARVALHO, C. et al,2005).

O Acinetobacter baumannii, antes considerado um micro-organismo de baixa virulência, figura ultimamente como uma das espécies patogênicas mais frequentemente isoladas de amostras clínicas e de ambiente hospitalar, comprometendo principalmente 
pacientes graves em UTIs. Neste ambiente confluem alguns fatores de risco para aquisição desta bactéria, inicialmente, por ser um local onde existe maior densidade de pacientes e de profissionais de saúde, bem como onde ocorrem inúmeros procedimentos diagnósticos e terapêuticos invasivos por paciente, além disso, é onde existe a maior utilização de antimicrobianos do hospital. Essa bactéria pode causar infecção em qualquer órgão do organismo e o sítio anatômico mais comumente acometido é o trato respiratório, sendo atualmente, junto com o $S$. aureus, $P$. aeruginosa e enterobactérias os micro-organismos mais rotineiramente envolvidos na etiologia de pneumonia nosocomial. Além disso, esta bactéria apresenta potencial habilidade para desenvolver resistência aos antimicrobianos de forma extremamente rápida (PONTES, 2006; RODRIGUES; PAZ; DE FREITAS et al, 2013; SANTOS et al. 2016).

A Klebsiella pneumoniae é encontrada no homem saudável colonizando a orofaringe e intestinos (fezes). No entanto, quando estes indivíduos apresentam baixa da imunidade em ambiente de UTI e estão mais suscetíveis em virtude de "portas de entradas" como feridas de decúbito, cânula de traqueostomia, tubo orotraqueal, sonda vesical de demora e cateter venoso central, esta bactéria passa de microbiota normal para patogênica causando IRAS (DESIMONI et al., 2004; MARTINEZ et al., 2004; MACIEL; MATTOS, 2013). A Klebsiella pneumoniae em ambiente de UTI pode causar pneumonia associada à ventilação mecânica, infecção de corrente sanguínea, infecção do trato urinário e infecção de partes moles dentre outros tipos de infecção. Entre os pacientes mais vulneráveis em relação a este microorganismo, destacam-se aqueles com co-morbidades, incluindo pacientes neutropênicos, transplantados e em ventilação mecânica. O longo período de internação em UTI proporciona um risco elevado para aquisição de IRAS por esta bactéria, bem como para colonização de bactérias multirresistentes (OLIVEIRA, et al,2010; COTRIM, E. R.; ROCHA, R. D. R.; FERREIRA, MFR. 2012).

No contexto mundial, constata-se que os micro-organismos resistentes aos antimicrobianos estão emergindo progressivamente. Tal situação tem causado considerável apreensão no ambiente hospitalar, seja pelo tempo que o paciente permanece internado, pelo custo do tratamento, pela limitante disponibilidade de medicamentos realmente eficazes e ainda pela iminência de óbito dos pacientes. É importante ainda ressaltar que os pacientes de UTI, em virtude de sua condição crítica, estão mais propensos a IRAS variadas, notadamente por micro-organismos multirresistentes. Estudos referem que até $50 \%$ das infecções nas UTIs estão associadas ao uso de dispositivos invasivos, e têm como agentes etiológicos microorganismos resistentes, sendo o Acinetobacter sp., Pseudomonas sp., Klebsiella sp., 
Staphylococcus aureus resistentes à meticilina (MRSA) e Escherichia coli, os mais frequentemente encontrados (OLIVEIRA et al, 2010).

\section{Principais sítios anatômicos acometidos por IRAS em UTI}

Nos 14 artigos analisados, podem-se observar os principais sítios anatômicos acometidos por IRAS em UTI. Conforme pode ser visualizado na Figura 1, verificou-se a superioridade dos casos de IRAS pela via do trato respiratório e trato urinário, com 33,2\% e $31 \%$ dos casos descritos respectivamente. As infecções de corrente sanguínea e sepse perfazem um total de $14,3 \%$ e $11,9 \%$ dos casos analisados respectivamente.

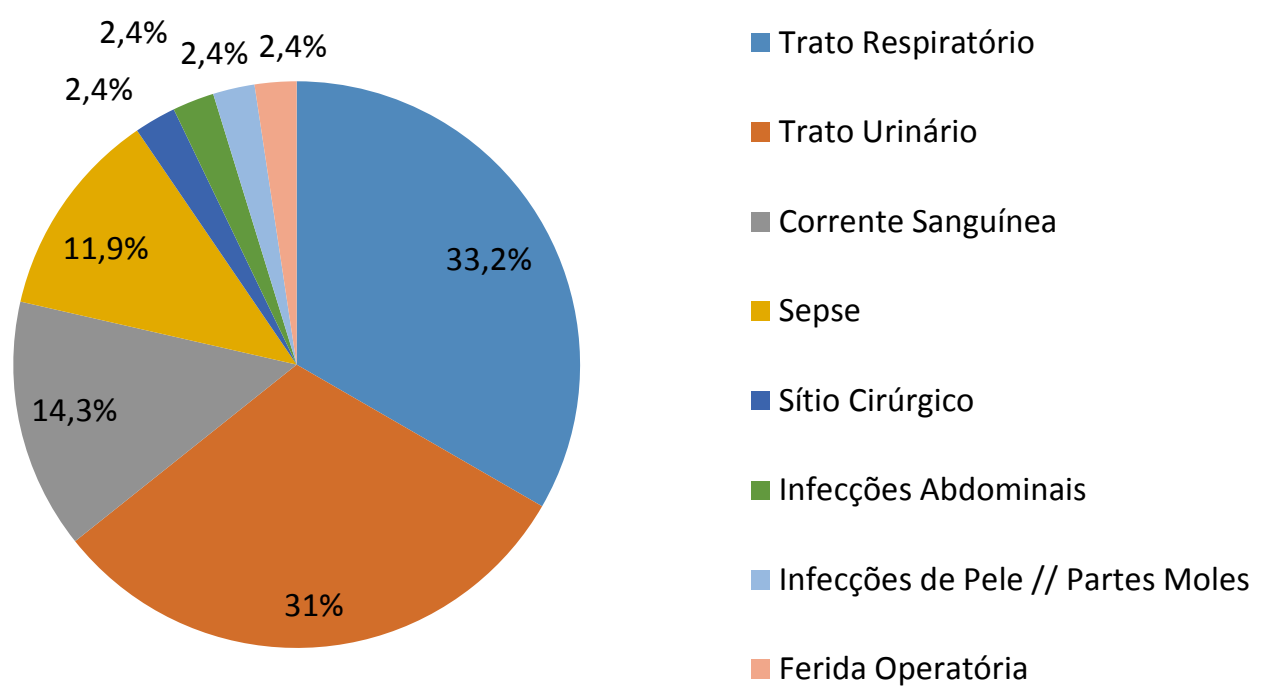

Figura 1. Principais sítios anatômicos acometidos por IRAS em UTI distribuídos entre os artigos selecionados $(\mathrm{N}=14)$ no período compreendido entre 2000 a 2016.

Alguns fatores, considerados de risco, propiciam a ocorrência de IRAS em pacientes UTI, sendo os mais frequentes os procedimentos invasivos. Entre os tipos de infecções que circulam neste ambiente destacam-se aquelas que atingem o trato respiratório como as pneumonias (geralmente associada a ventilação mecânica), as infecções do trato urinário (associada a dispositivos intravesicais) e as infecções de corrente sanguínea (principalmente associada Cateter Venoso Central) (DE OLIVEIRA et al, 2010).

$\mathrm{Na}$ análise dos artigos verifica-se que o trato respiratório é o principal sítio anatômico acometido por IRAS em UTIs. Sabe-se que a as infecções do trato respiratório normalmente ocorrem após 48 horas ou mais de internação na unidade. É ocasionada principalmente 
quando o paciente apresenta imunossupressão, ou por invasão de patógenos no trato respiratório resultando em na anulação das defesas naturais ou quando o micro-organismo apresenta alta virulência. A intubação é um procedimento invasivo que reduz a eficácia das defesas nasais e pulmonares, sendo assim pacientes intubados e criticamente enfermos apresentam um risco particularmente elevado de desenvolver infecção como a pneumonia nosocomial. Observa-se que a incidência de pneumonia é de 7 a 21 vezes maior em indivíduos intubados do que nos não submetidos ao procedimento. Dentre as IRAS, a infecções respiratórias são consideradas as principais causa de óbitos em UTIs, variando entre 20 e $70 \%$. Os piores prognósticos envolvem as bactérias $P$. aeruginosa e A. baumannii bem como as bactérias multirresistentes. No entanto, a mortalidade é menos frequente quando associada a bactérias sensíveis aos medicamentos (GARCIA et al., 2007; MARTINS et al., 2008; LOPES E LÓPEZ 2009).

Já as Infecções do Trato Urinário (ITU) são responsáveis por cerca de 35 a 45\% das IRAS em UTIs, sendo que $80 \%$ estão relacionadas ao uso do cateter vesical de demora. Os fatores de risco associados ao surgimento de ITU variam a partir do método utilizado, da susceptibilidade do paciente e do manuseio com o cateter antes e durante a realização do procedimento. Os procedimentos invasivos como o cateterismo vesical, indicado na maioria das vezes para avaliação do débito urinário, e em pacientes comatosos e sedados, tornam as ITU manifestações frequentes em ambiente de UTI. Existem estudos que mostram que, em curto espaço de cateterismo vesical, a urina previamente estéril torna-se colonizada por bactérias. Os pacientes gravemente enfermos desenvolvem infecções urinárias associadas ao cateterismo vesical principalmente por Enterobactérias, P. aeruginosa e Enterococcus spp (LUCCHETTI, GIANCARLO et al, 2005; VIEIRA, 2009; MARRA A; BARBOSA O; BARSANTI WS, 2009).

A mucosa uretral quando danificada por um cateterismo vesical mal realizado possibilita a penetração de micro-organismos, podendo originar uma infecção local ou até mesmo progredir para uma complicação mais grave como a bacteremia. A inserção do cateter vesical possibilita a instalação de infecções, uma vez que micro-organismos colonizados na uretra podem ser inseridos juntamente com o cateter para a bexiga. Em indivíduos sadios, os mecanismos naturais de defesa têm a competência de eliminar a população bacteriana introduzida, já nos pacientes hospitalizados, os riscos para adquirir infecção é mais elevado, devido estarem mais vulneráveis (LENZ, 2006).

Para os pacientes internados em UTIs, além do cateterismo vesical, as ITU estão relacionadas fatores como a virulência bacteriana, fatores relacionados ao hospedeiro 
(microbiota normal), pH urinário, alta concentração de ureia, ácidos orgânicos, bem como fatores genéticos e alterações anatomo-funcionais no trato urinário. Fatores predisponentes, como técnicas de assepsia e de sondagem vesical, e de tempo de sondagem também devem ser considerados, sendo assim, é necessário que a UTI implante medidas para minimizar a incidência e os riscos destas infecções, prevenindo-as pelo aprimoramento técnico-científico de sua equipe (SOUZA NETO et al., 2008; VIEIRA, 2009).

Os cateteres vasculares centrais (CVC) são dispositivos invasivos indispensáveis para o tratamento e cuidado de pacientes críticos hospitalizados em UTIs e estão intimamente relacionados às infecções de corrente sanguínea. No entanto, seu uso predispõe os pacientes a desenvolverem infecções locais ou sistêmicas. Alguns aspectos como: o tipo de cateter, a frequência da manipulação e os fatores relacionados ao estado geral do paciente interferem na incidência destas infecções. Embora as infecções de acesso vascular ocorram em menor frequência quando comparadas às de outros sítios como: pneumonia (associada a ventilação mecânica), infecção urinária e feridas operatórias, elas apresentam maior morbimortalidade. Existem relatos de que aproximadamente $50 \%$ das infecções de corrente sanguínea ocorrem pelo CVC (NETTO et al, 2009).

Alguns fatores de risco podem estar associados ao uso CVC como: duração do uso do acesso vascular, local do sítio de inserção, idade inferior a um ano ou superior a 60 anos, gênero feminino, queimaduras, antibioticoterapia, uso de medicamentos imunossupressores, presença de foco infeccioso à distância, gravidade da doença de base e tempo de hospitalização prévia, entre outros (CENTERS FOR DISEASE CONTROL AND PREVENTION et al, 2002).

No momento da inserção do cateter as bactérias presentes na pele podem invadir a corrente sanguínea levando a quadros de bacteremia, no entanto, o acesso das bactérias também podem ocorrer por: contaminação das conexões entre o sistema de infusão e o acesso vascular; infusão de soluções contaminadas utilizadas para manter a permeabilidade do cateter; por via hematogênica de outro foco infeccioso à distância; por transdutores contaminados utilizados para monitoração hemodinâmica dos pacientes e pelas mãos contaminadas dos profissionais de saúde (TENÓRIO et al., 2007; ABREU et al., 2008; NETO et al, 2009).

\section{Medidas de controle de IRAS em UTI}


Diante dos pacientes gravemente enfermos internados em UTIs, é fundamental que toda a equipe de profissionais de saúde que circulam no hospital/UTI realize rigorosamente práticas de prevenção de IRAS. A educação contínua através de processos de treinamento da equipe assistencial deve ser promovida pela direção do hospital sistematicamente, bem como o desenvolvimento de políticas de controle realmente eficazes a fim de se evitar infecções. Entre as principais medidas de prevenção de IRAS pode-se ressaltar a lavagem adequada das mãos, o isolamento de doenças transmissíveis e medidas particulares para cada sítio anatômico (SIVASTRAVA; SHETTY, 2007; ROMANELLI et al., 2013).

A higienização das mãos (HM) é uma das medidas de controle de IRAS mais simples, financeiramente viáveis e eficientes a serem realizadas pelos profissionais de saúde em âmbito hospitalar. Recomenda-se que a HM seja realizada antes e após a manipulação de cada paciente no leito (higienização, troca de roupas), na administração de medicamentos orais ou injetáveis e ainda no manuseio de equipamentos. Para realizar adequadamente a HM, deve-se priorizar o uso de sabões líquidos com antimicrobianos como a clorexidina ou iodo e obedecer rigorosamente a técnica de lavagem, friccionando vigorosamente as mãos por no mínimo por 10 a 15 segundos, inclusive na região interdigital e unhas. De acordo com a RDC/ANVISA n 42/2010 é obrigatória a disponibilidade de preparação alcoólica para fricção antisséptica das mãos para os profissionais de saúde nos pontos de assistência e tratamento, em local visível e de fácil acesso (ZELENITSKY et al., 2000; MACHADO et al., 2001; CAMPOS; MARTINEZ; NOGUEIRA, 2009; ANVISA 2017).

Neste contexto, o uso de EPIs também é fundamental para minimizar a presença de micro-organismos no ambiente hospitalar. É essencial a disponibilização de luvas estéreis e não estéreis em todas as áreas do hospital. Uma vez utilizadas de forma adequada, protegem o profissional à exposição com material infectante, bem como impedem a veiculação de microorganismos ao paciente. O uso de máscara, óculos de proteção e jaleco devem ser categoricamente exigidos, principalmente no caso de procedimentos nos quais o risco de contato com material biológico é presumível (BELTRAMI et al., 2000; MACHADO et al., 2001).

O termo "isolamento" de doenças transmissíveis, hoje denominado de "precauções", são medidas adotadas no ambiente hospitalar/UTI com a finalidade de impedir a transmissão de micro-organismos dos pacientes contaminados para outros pacientes, bem como para visitantes e profissionais de saúde. Além disso, a adoção destas medidas visa reduzir o tempo e o custo de internação do paciente. As precauções denominadas de específicas devem ser cumpridas quando se sabe que a doença apresenta uma forma específica de transmissão. 
Sendo assim, é importante identificar qual a via de contaminação, seja por contato ou pela via respiratória, devem-se utilizar os EPIs específicos como luvas descartáveis (ao manipular o paciente e/ou objetos pertencentes a ele) e máscaras simples e/ou com filtro. Uma vez que o profissional utiliza os EPIs necessários e adequados no atendimento, o resultado é o controle eficiente da transmissão de micro-organismos no ambiente hospitalar (APECIH 2012).

$\mathrm{Na}$ verdade, para minimizar a densidade de IRAS em pacientes de UTI, seria importante que medidas específicas de prevenção fossem desenvolvidas para cada local do sítio anatômico de inserção. Dessa forma, recomenda-se implementação dos bundles. Os bundles consistem basicamente em um protocolo de medidas preventivas de cuidados com o paciente para serem aplicados de forma multidisciplinar dentro das UTIs e auditados pelas CCIHs. A utilização de bundles específicos para cada via de infecção funciona como uma estratégia extremante eficaz para aprimorar o atendimento e garantir a segurança dos internos em UTIs, sendo sua finalidade principal restringir as taxas de mortalidade e o tempo de internação (MENDONÇA, 2009; ANVISA, 2013).

A implementação da $\mathrm{CCIH}$ nos hospitais, sobretudo em UTIs, diminuem significativamente os níveis das IRAS, criando um ambiente seguro para o paciente e evitando infecções no decorrer da internação. Conforme a Portaria MS nº 2616/1998, o hospital deve constituir a $\mathrm{CCIH}$ com membros designados formalmente, estes, devem ser profissionais da área de saúde, de nível superior, com o objetivo de esquematizar, organizar, implementar, manter e avaliar o Programa de Controle de Infecção Hospitalar (PCIH), de forma a adequá-lo às particularidades e necessidades do hospital (BRASIL, 1998; MARUYAMA; OLIVEIRA, 2008).

\section{Conclusão}

No intuito de descrever os principais micro-organismos causadores de IRAS em UTIs, foram selecionados e analisados 14 artigos com critérios de inclusão bem fundamentados. Dessa forma, verificou-se a presença de 42 micro-organismos como os principais responsáveis por IRAS nestas unidades. Dentre os 42 micro-organismos encontrados causando IRAS em UTI destacam-se a Pseudomonas aeruginosa, Staphylococcus aureus, Acinetobacter baumanni e a Klebsiella pneumoniae.

$\mathrm{Na}$ análise também foi possível identificar os sítios anatômicos predominantes das IRAS em UTIs. Sendo assim, verificou-se a superioridade dos casos de IRAS pela via do trato respiratório, seguidas das infecções do trato urinário e de corrente sanguínea. 
Em face aos resultados descritos, é de fundamental importância apresentar medidas preventivas em relação às IRAS em ambiente de UTI, pois mesmo diante conhecimento dos profissionais de saúde em relação às práticas de prevenção neste ambiente, a adesão destas medidas pelos indivíduos nos serviços de saúde ainda é muito elementar. A fim de se evitar infecções, os profissionais envolvidos devem redobrar a vigilância e a cautela quanto ao uso de práticas assépticas, constante lavagem das mãos e uso controlado de técnicas invasivas na rotina dos cuidados. Além disso, fica evidente a importância da implementação de programas de prevenção bem como da presença efetiva das CCIHs nos hospitais a fim de reduzir os casos existentes.

\section{REFERÊNCIAS}

ABREU, K. E. O. et al. Infecção hospitalar em uma unidade de terapia intensiva de um hospital público. Revista do Hospital Universitário UFMA, v. 9, 31-36p., Maranhão, 2008. Disponível em:< http://www.scielo.br/scielo.php?pid=S0104$11692010000200014 \&$ script=sci_abstract\&tlng=pt $>$. Acesso em:18 abr. 2018.

ABREU, K. E. O. et al. Infecção hospitalar em uma unidade de terapia intensiva de um hospital público. Revista do Hospital Universitário/UFMA, v. 9, 31-36 p., São Luís, 2008. Disponível em: <http://rbti.org.br/artigo/detalhes/0103507X-24-4-15>. Acesso em: 22 ago. 2018.

ANBIO. Agência Nacional de Biossegurança. Biossegurança hospitalar. 2012. Disponível em:<http://www.anbio.org.br> Acesso em: 20 maio 2018, 16:55:02.

APECIH - Associação Paulista de Epidemiologia e Controle de Infecção Relacionada à Assistência à Saúde. Precauções e isolamento relacionada à assistência da saúde. São Paulo. 2017. Disponível em: http://portal.anvisa.gov.br/documents /Caderno+4++Medidas+de+Preven\%+infec>. Acesso em: 28 ago. 2018.

BARBOSA, M. E. M.; SIQUEIRA, D. C.; MANTOVANI, M. F. Controle de infecção hospitalar no Paraná: Facilidades e dificuldades do enfermeiro. Revista SOBECC, v. 17, n. 3, 
50-59p., São Paulo, 2012. Disponível em: http://www. Sobecc. org. br/arquivos/ artigos/2012/Arquivos/artigos/2.pdf. Acesso em: 24 maio 2018, 14:27:02.

BARROS, L. M. et al. Prevalência de micro-organismo e sensibilidade antimicrobiana de infecções hospitalares em unidade de terapia intensiva de hospital público no Brasil. Revista de Ciências Farmacêuticas Básica e Aplicada, v. 33, n. 3, p. 429-435, Fortaleza, 2012. Disponível em: http://serv-

bib.fcfar.unesp.br/seer/index.php/Cien_Farm/article/viewFile/2211/1267. Acesso em: 22 maio 2018.

BARROS, L. M. et al. Prevalência de micro-organismo e sensibilidade antimicrobiana de infecções hospitalares em unidade de terapia intensiva de hospital público no Brasil. Revista de Ciências Farmacêuticas Básica e Aplicada, v. 33, n. 3, p. 429-435, Fortaleza, 2012. Disponível em: <http://200.145.71.150/seer/index.php/Cien_Farm/ article/viewFile/2211/1267>. Acesso em: 17 ago. 2018, 13:21:22.

BELTRAMI, E. M. et al. Risk and management of blood-borne infections in health care workers. Clinical microbiology reviews, v. 13, n. 3, p. 385-407, , Atlanta, 2000. Disponível em: <http://cmr.asm.org/content/13/3/385.short>. Acesso em: 15 set. 2018, 15:20:11.

BICUDO, E. L. et al. Nosocomial outbreak of Pantoea agglomerans in a pediatric urgent care center. Brazilian Journal of Infectious Diseases, v. 11, n. 2, p. 281-284, Brasília , 2007. Disponível em: <http://www.scielo.br/scielo.php?pid=S141386702007000200023\&script=sci_arttext\&tlng=pt>. Acesso em 14 out. 2018, 22:01:33.

BRASIL. Agência Nacional De Vigilância Sanitária. Medidas de Prevenção de Infecção Relacionada à Assistência à Saúde. Série Segurança do Paciente e Qualidade em Serviços de Saúde. Brasília, DF: Anvisa, 2017. Disponível em:

<http://portal.anvisa.gov.br/documents/33852/3507912/Caderno+4++Medidas+de+Preven\%C $3 \% \mathrm{~A} 7 \% \mathrm{C} 3 \% \mathrm{~A} 3 \mathrm{o}+\mathrm{de}+\mathrm{Infec} \% \mathrm{C} 3 \% \mathrm{~A} 7 \% \mathrm{C} 3 \% \mathrm{~A} 3 \mathrm{o}+$ Relacionada+\%C3\%A0+Assist\%C3\%AAn cia+\%C3\%A0+Sa\%C3\%BAde/a3f23dfb-2c54-4e64-881c-fccf9220c373>. Acesso em: 23 ago. 2018, 22:07:03. 
BRASIL. Agência Nacional de Vigilância Sanitária. Medidas de Prevenção de Infecção

Relacionada à Assistência à Saúde. Brasília: Anvisa, 2017. Disponível em:

$<$ http://portal.anvisa.gov.br/documents/33852/3507912/Caderno+4+-+Medidas+de

+ Preven\%C3\%A7\%C3\%A3o+de+Infec\%C3\%A7\%C3\%A3o+Relacionada+\%C3\%A0+Assis

t\%C3\%AAncia+\%C3\%A0+Sa\%C3\%BAde/a3f23dfb-2c54-4e64-881c-fccf9220c373>.

Acesso em 15 out. 2018, 12:08:45.

BRASIL. Agência Nacional de Vigilância Sanitária. Segurança do Paciente em Serviços de Saúde: Higienização das Mãos. Brasília: Anvisa, 2009. Disponível em:

<http://bvsms.saude.gov.br/bvs/publicacoes/seguranca_paciente_servicos_saude_higienizacao _maos.pdf>. Acesso em: 15 set. 2018, 15:20:11.

BRASIL. Ministério da Saúde. Portaria nº. 2616, de 12 de maio de 1998. Aprova o programa de controle de infecção hospitalar e dá outras providências. Diário Oficial da República Federativa do Brasil, Brasília, 13 de maio 1998. Seção 1. Disponível em:

<http://bvsms.saude.gov.br/bvs/saudelegis/gm/1998/prt2616_12_05_1998.html>. Acesso em: 15 set. 2018, 22:44:01.

CAMPOS, L. A.; MARTINEZ, M. R.; NOGUEIRA, P. C. Adesão à técnica de lavagem de mãos em Unidade de Terapia Intensiva Neonatal. Revista Paulista de Pediatria. v.27, n.2, p.179-85, São Paulo, 2009. Disponível em: <http://www.scielo. br/pdf/rpp/v27n2/10. Acesso em: 03 abr. 2017, 20:17:12.

CÂNDIDO, R. B. R et al. Avaliação das infecções hospitalares em pacientes críticos em um Centro de Terapia Intensiva. Revista da Universidade Vale do Rio Verde, Minas Gerais, 2012. Disponível em:< http://www.uricer.edu.br/site/pdfs/perspectiva/1002_410.pdf>. Acesso em: 23 ago. 2018

CARVALHO, C. E. et al. Monitoramento microbiológico sequencial da secreção traqueal em pacientes intubados internados em unidade de terapia intensiva pediátrica. Jornal de

Pediatria, v. 81, n. 1, 29-33p., Rio de Janeiro, 2005. Disponível em:

<http://www.scielo.br/pdf/\%0D/jped/v81n1/v81n1a07.pdf>. Acesso em: 22 set. 2018, 11:15:53. 
CENTERS FOR DISEASE CONTROL AND PREVENTION. Guidelines forthepreventionofintravascularcatheter-relatedinfections. MMWR, Atlanta, 2002. Disponível em: <https://www.cdc.gov/mmwr/previe/mmwrhtml/rr5110a1.htm?vm=r >. Acesso em: 11 set. 2018, 17:34:33.

COTRIM, É. R.; ROCHA, R. D. R.; FERREIRA, M. F. R. Klebsiella Pneumoniae Carbapenemase-KPC em Enterobacteriaceae: o desafio das bactérias multirresistentes. Revista do Centro Universitário Newton Paiva, v. 5, n. 1, Beloo Horizonte, 2012. Disponível em: <http://blog.newtonpaiva.br/pos/wpcontent/uploads/2013/04/PDF-E5-S39.pdf>. Acesso em: 13 set. 2018, 07:54:03.

COUTO, R. C.; PEDROSA, T. M.G.; NOGUEIRA, J. M. Infecção hospitalar: epidemiologia, controle e tratamento. Rio de Janeiro: MEDSI, p. 234-56, 2003.

FAVARIN, S. S.; CAMPONOGARA, S. Perfil dos pacientes internados na unidade de terapia intensiva adulto de um hospital universitário. Revista de Enfermagem da UFSM, v. 2, n. 2, 320-329p., Santa Maria, 2012. Disponível em:<https://periodicos.ufsm.br/reufsm/article/view/5178/3913>. Acesso em: 18 abr. 2018.

FIGUEIREDO, D. A.; VIANNA, R. P. T.; NASCIMENTO, J. A. Epidemiologia da infecção hospitalar em uma Unidade de Terapia Intensiva de um hospital público municipal de João Pessoa-PB. Revista Brasileira de Ciências da Saúde, v. 17, n. 3, 233-240p., João Pessoa, 2013. Disponível em: < https://periodicos.ufpb.br/ojs2/index.php/rbcs/article/view/12527>. Acesso em 18 abr. 2018.

FRANÇA, C. D. M.; ALBUQUERQUE, P. R.; SANTOS, A. C. B. C. Perfil epidemiológico da unidade de terapia intensiva de um Hospital Universitário. Revista InterScientia, v. 1, n. 2, João Pessoa, 2013. Disponível em: <https://periodicos.unipe .br/index.php/interscientia/article/view/37/34>. Acesso em: 07 abr. 2018, 07:11:03.

GLOWACKI, C. M. et al. Identificação de microrganismos isolados de superfícies inanimadas de contato de uma unidade de pronto atendimento. Anais do EVINCI-UniBrasil, v. 1, n. 4, 152-161p., Curitiba, 2016. Disponível em: 
$<$ http://portaldeperiodicos.unibrasil.com.br/index.php/anaisevinci/article/view/863/0>. Acesso em $: 15$ out. 2018, 06:47:02.

GRAY, J.; OMAR, N. Nosocomial infections in neonatal intensive care units in developed and developing countries: how can we narrow the gap? Journal of Hospital Infection, v. 83, n. 3, p. 193-195, Birmingham2013. Disponível em:

$<$ https://www.journalofhospitalinfection.com/article/S0195-6701 (12)004288/abstract?

Code=join-site $>$. Acesso em: 04 de maio de 2018.

GUEDES, M. et al. Adesão dos profissionais de enfermagem à higienização das mãos: uma análise segundo o modelo de crenças em saúde. Cogitare Enfermagem, v. 17, n. 2, Paraná, 2012. Disponível em: <https://revistas.ufpr.br/cogitare/article/view/27886/18494> Acesso em: 07 abr. 2018.

LEISER, J. J.; TOGNIM, M. C. B.; BEDENDO, J. Infecções hospitalares em um centro de terapia intensiva de um hospital de ensino no norte do Paraná. Ciência, cuidado e saúde, v. 6, n. 2,181-186p., Paraná, 2007. Disponível em: <http://bases.bireme.br/cgibin/wxislind.exe/iah/online/?IsisScript=iah/iah.xis\&src=google \&base=BDENF\&lang=p\&nex tAction=lnk\&exprSearch=18999\&indexSearch=ID>. Acesso em: 18 ago. 2018.

LENZ, L. L. Cateterismo vesical: cuidados, complicações e medidas preventivas. Arquivos Catarinenses de Medicina, v. 35, n. 1, 82-91p., Rio de Janeiro, 2006. Disponível em: $<$ http://www.acm.org.br/revista/pdf/artigos/361.pdf>. Acesso em 15 out. 2018, 10:12:23.

LIMA, M. E.; ANDRADE, D.; HAAS, V. J. Avaliação prospectiva da ocorrência de infecção em pacientes críticos de unidade de terapia intensiva. Revista brasileira de terapia Intensiva, v. 19, n. 3, 342-7p., Ribeirão preto, 2007. Disponível em: <http://www.scielo.br/pdf/rbti/v19n3/v19n3a13.pdf>. Acesso em: 28 ago. 2018.

LISBOA, T. C et al. Prevalência de infecção nosocomial em Unidades de Terapia Intensiva do Rio Grande do Sul. Revista brasileira de terapia intensiva, v. 19, n. 4, 414-420p., Rio grande do Sul, 2007. Disponível em: < http://www.scielo.br/pdf/rbti/v19n4/a02v19n4.pdf >. Acesso em: 18 abr. 2018. 
LOPES, F.M.; LÓPEZ, M. F. Impacto do sistema de aspiração traqueal aberto e fechado na incidência de pneumonia associada à ventilação mecânica: revisão de literatura. Revista brasileira terapia intensiva, v. 21, n. 1, 80-8p., Salvador, 2009. Disponível em: <http://www.scielo.br/pdf/rbti/v21n1/v21n1a12>. Acesso em 17 out. 2018, 09:54:11.

LUCCHETTI, Giancarlo et al. Infecções do trato urinário: análise da frequência e do perfil de sensibilidade dos agentes causadores de infecções do trato urinário em pacientes com cateterização vesical crônica. Jornal Brasileiro de Patologia Medicinal Laboratorial, v. 41, n. 6, 383-9p., São Paulo, 2005. Disponível em:

<http://www.scielo.br/pdf/\%0D/jbpml/v41n6/a03v41n6.pdf>. Acesso em 17 out. 2018, 11:21:09.

MACHADO, A. et al. Prevenção da infecção hospitalar. Projeto Diretrizes ABM, 16-17p., São Paulo, 2001. Disponível em: <https://www.researchgate.net/ profile/Alvaro_Ferraz2 /publication/237238421_Sociedade_Brasileira_de_Infectologia /links/5469daf40cf2397f782dd210.pdf>. Acesso em 17 out. 2018, 17:45:55.

MARRA, A.; BARBOSA, O.; BARSANTI, W. S. Controle do foco, diagnóstico e tratamento. Consenso Brasileiro de Sepse: disfunção de múltiplos órgãos, Hospital IsraelitaAlbertEinstein, São Paulo, 2003. Disponível em: <http://www.laadti.unifesp. br/2.pdf>. Acesso em 20 out. 2018, 20:13:02.

MARTINS, K. M. et al. Adesão às medidas de prevenção e controle de infecção de acesso vascular periférico pelos profissionais da equipe de enfermagem. Ciência, Cuidado e Saúde, v. 7, n. 4, 485-492p., Goiânia, 2008. Disponível em:

<http://ojs.uem.br/ojs/index.php/CiencCuidSaude/article/view/6634>. Acesso em 21 out. 2018, 00:25:54.

MARUYAMA, S. A. T.; OLIVEIRA, R. Controle de Infecção Hospitalar: histórico e papel do estado. Revista eletrônica de enfermagem, v.10, n.3, Cuiabá, 2008. Disponível em: <https://www.revistas.ufg.br/fen/article/view/46642>. Acesso em 22 out. 2018, 06:34:23. 
MENDONÇA, M. et al. Serviço de controle de infecções hospitalares na prevenção da pneumonia associada à ventilação mecânica. Prática Hospitalar, Florianópolis, 2009; .Disponível em:<http://www.scielo.br/pdf/tce/v21n4/14.pdf > Acesso em: 05 nov. 2018. MENEGOTTO, F. R.; PICOLI, S. U. Staphylococcus aureus oxacilina resistente (MRSA): incidência de cepas adquiridas na comunidade (CA-MRSA) e importância da pesquisa e descolonização em hospital. Revista Brasileira de Analises Clinícas, v. 39, n. 2, 147-150p., São Paulo, 2007. Disponível em: <https://www.researchgate.net/profile /Simone_Picoli/publication/237365926_pdf>. Acesso em 21 out. 2018, 08:12:09.

MOURA, M. E. B, et al. Infecção hospitalar: estudo de prevalência em um hospital público de ensino. Revista Brasileira de Enfermagem, v. 60, n. 4, Brasília, 2007. Disponível em: <http://www.redalyc.org/html/2670/267020026018/>. Acesso em: 15 ago, 2018, 11:40:13.

MOURA, M. E. B. et al. As representações sociais das infecções hospitalares elaboradas pelos profissionais de saúde. Revista Brasileira de Enfermagem, Brasília 2008. Disponível em: <http://www.saudedireta.com.br/ docsupload/13403639784552_58.pdf>. Acesso em: 04 maio de 2018.

MOURA, M. E. B. et al. Infecção hospitalar: estudo de prevalência em um hospital público de ensino. Revista Brasileira de Enfermagem, v.60, n.4, 416-42p., Brasília, 2007.

Disponível em:< http://www.scielo.br/pdf/reben/v60n4/a11.pdf>. Acesso em: 18 abr. 2018.

NETTO, S. M. et al. Infecção de cateter vascular central em pacientes adultos de um centro de terapia intensiva. Revista Gaúcha De Enfermagem, Porto Alegre, 2009. Disponível em: <https://www.lume.ufrgs.br/handle/10183/23638>. Acesso em 24 out. 2018, 10:43:40.

NOGUEIRA, P. S. F et al. Perfil da infecção hospitalar em um hospital universitário. Revista de enfermagem UERJ , v. 17, n. 1, p. 96-101, Rio de janeiro, 2009. Disponível em: < http://www.facenf.uerj.br/v17n1/v17n1a18.pdf>. Acesso em: 17 maio 2018.

NOGUEIRA, P. S. F. et al. Perfil da infecção hospitalar em um hospital universitário. Revista de enfermagem UERJ, v. 17, n. 1, 96-101p., Rio de Janeiro, 2009. Disponível em: <http://files.bvs.br/upload/S/0104-3552/2009/v17n1/a017.pdf>. Acesso em: 21 ago. 2018, 09:37:45. 
OLIVEIRA, A. C. Resistência bacteriana e mortalidade em um centro de terapia intensiva. Revista Latino-Americana de Enfermagem, v. 18, n. 6, p. 1152-1160, Belo Horizonte, 2010. Disponível em:<http://www.revistas.usp.br/rlae/article/view/4270/ 5402>. Acesso em: 03 abr. 2018.

OLIVEIRA, A. C.; KOVNER, C. T.; SILVA, R. S. Infecção hospitalar em unidade de tratamento intensivo de um hospital universitário brasileiro. Revista Latino-Americana de Enfermagem, v. 18, n. 2, Belo Horizonte, 2010. Disponível em:

<http://www.redalyc.org/html/2814/281421932014/>. Acesso em: 02 set. 2018, 22:12:56.

ORGANIZAÇÃO MUNDIAL DA SAÚDE (OMS), 2008. Organização Panamericana da Saúde. Infecção hospitalar. Disponível em: <www.opas.org.br/sistema/fotos/ hospitala>. Acesso em: 05 maio 2018.

PADRÃO, M. C. et al. Prevalência de infecções hospitalares em unidade de terapia intensiva. Revista da sociedade brasileira de clinica medica, São Paulo, 2010. Disponível em: < http://bases.bireme.br/cgibin/wxislind.exe/iah/online/?IsisScript=iah/iah.xis\&src=google\&base=LILACS\&lang=p\&nex tAction=lnk\&exprSearch=543997\&indexSearch=ID>. Acesso em: 19 abr. 2018.

PEREIRA, M. S. et al. Controle de Infecção Hospitalar em Unidade de terapia Intensiva: desafios e perspectivas. Revista Eletrônica de Enfermagem, v. 2, n. 1, Goiânia, 2000. Disponível em: <http://www.fen.ufg.br/revista/revista2_1/IH.html〉. Acesso em: 15 Març. 2018.

PILONETTO, M. et al. Hospital gowns as a vehicle for bacterial dissemination in an intensive care unit. Brazilian Journal of Infectious Diseases, v. 8, n. 3, 206-210p., Curitiba, 2004. Disponível em: <http://www.scielo.br/pdf/bjid/v8n3/21617.pdf>. Acesso em 26 fev. 2018 .

PONTES, V. M. O.; MENEZES, E. A.; CUNHA, M. R. F. A.; SALVIANO, M. N. C.; OLIVEIRA, I. R. N. Perfil de Resistência de Acinetobacter baumannii a Antimicrobianos nas Unidades de Terapia Intensiva e Semi-intensiva do Hospital Geral de Fortaleza. Revista Brasileira de Análises Clínicas, Fortaleza, 2006; v. 38, p. 123-26. Disponível em: < 
http://revistas.cff.org.br/?journal=infarma\&page=article\&op $=$ view\&path\%5B $\% 5 \mathrm{D}=474>$. Acesso em: 28 maio 2018.

RENNER, J. D. P; CARVALHO, È. D. Microrganismos isolados de superfícies da UTI adulta em um hospital do Vale do Rio Pardo-RS. Revista de Epidemiologia e Controle de Infecção, v. 3, n. 2, 40-44p., Rio Grande do Sul, 2013. Disponível em: http://online. unisc. br/seer/index.php/epidemiologia/article/view/3290>. Acesso em 26 out. 2018, 11:09:58.

RODRIGUES, A. M. X.; PAZ, I. F. R.; FREITAS, R. M. Problemas Relacionados com Antimicrobianos em UTI em um Hospital Público de Teresina. Revista Multiprofissional em Saúde do Hospital São Marcos, v. 1, n. 1, 40-9p., Teresina, 2013. Disponível em: <http://ojs.saomarcos.org.br/ojs/index.php/cientifica/article/view/13>. Acesso em: 29 ago. 2018.

RODRIGUES, A. M. X.; PAZ, I. F. R.; FREITAS, R. M. Problemas Relacionados com Antimicrobianos em UTI em um Hospital Público de Teresina. Revista Multiprofissional em Saúde do Hospital São Marcos, Teresina, 2013. Disponível em: <http://ojs.saomarcos.org.br/ojs/index.php/cientifica/article/view/13>. Acesso em 26 out. 2018, 12:55:01.

ROMANELLI, R. M. C. et al. Infecções relacionadas a assistência à saúde baseada em critérios internacionais, realizada em unidade neonatal de cuidados progressivos de referência de Belo Horizonte, MG. Revista Brasileira de Epidemiologia, Belo Horizonte, 2013.Disponível em: <https://www.scielosp.org/scielo.php?pid=S1415790X2013000100077\&script=sci_arttext\&tlng=pt>. Acesso em 27 out. 2018, 21:34:02.

SANTOS, A. K. S. et al. Perfil microbiológico das infecções hospitalares nas unidades de terapia intensiva. Revista de enfermagem UFPE on line, v. 10, Teresina, 2016. Disponível em: <http://bases.bireme.br/cgi-bin/wxislind.exe/iah/online/ ?IsisScript $=$ iah/iah.xis\&src=google \&base $=$ BDENF\&lang=p\&nextAction=lnk\&exprSearch $=3$ 0229\&indexSearch=ID>. Acesso em: 28 out. 2018, 07:14:44.

SANTOS, A. K. S. et al. Perfil microbiológico das infecções hospitalares nas unidades de terapia intensiva. Revista de enfermagem UFPE, v. 10, n. 3, 1432-1440p., Pernambuco, 
2015. Disponível em: <

https://periodicos.ufpe.br/revistas/revistaenfermagem/article/download/11084/12529>.

Acesso em 18 abr. 2018.

SANTOS, A. L. et al. Staphylococcus aureus: visitando uma cepa de importância hospitalar. Jornal Brasileiro de Patologia e Medicina Laboratorial, v. 43, n. 6, p. 413-423p. Rio de Janeiro,2007. Disponível em:< http://www.scielo.br/pdf/jbpml/ v43n6/v43n6a05.pdf $>$. Acesso em: 26 maio 2018. 14:26:46.

SIVASTRAVA, S.; SHETTY, N. Healthcare-associated infections in neonatalunits: lessons from contrasting worlds. The Journal of Hospital Infection, Londres, 2007. Disponível em: <http://www.sciencedirect.com/science/article/pii/S01956701070 00400>. Acesso em: 27 set.2017.

SOUZA NETO, J. L. et al. Infecção do trato urinário relacionada com a utilização do catéter vesical de demora: resultados da bacteriúria e da microbiota estudadas. Revista do Colégio Brasileiro de Cirurgiões, Taubaté, 2008.Disponível em: <http://www. scielo.br/pdf/rcbc/v35n1/v35n1a08.pdf>. Acesso em 11 out. 2018, 11:24:56.

SOUZA, M. T; SILVA, M. D.; CARVALHO, R. Revisão integrativa: o que é e como fazer. Einstein, v. 8, 102-6 p., Três Lagoas, 2010. Disponível em: <http://www.scielo.br/ pdf/eins/v8n1/pt_1679-4508-eins-8-1-0102>. Acesso em: 03 set. 2018, 07:59:21.

VIEIRA, F. A. Ações de enfermagem para prevenção de infecção do trato urinário relacionada ao cateter vesical de demora. AlberteEinstein , São Paulo, 2009. Disponível em: <http://apps.einstein.br/revista/arquivos/PDF/632-Einstein\%2 0v7n3p372-5_port.pdf>. Acesso em 03 nov. 2018, 23:37:01.

VINCENT, J. L. Nosocomial infections in adult intensive-care units. The lancet, Atlanta, 2003. Disponível em: https://www.thelancet.com/pdfs/journals/lancet/ PIIS01406736(03)140810.pdf?code=lancet-site. Acesso em 07 abr. 2018. 
ZELENITSKY, S. A. et al. A prospective, randomized, double-blind studyof single high dose versus multiple standard dose gentamicin both in combination withmetronidazole for colorectal surgicalprophylaxis. Journal of Hospital Infection, v. Georgia, 2000. Disponível em: 〈https://www.journalofhospitalinfection.com /article/S0195-6701(00)90814-4/abstract>. Acesso em 11 nov. 2018, 08:35:54. 